\title{
Capital Investment Decision: Impact from Environmental Scanning
}

\author{
Nik Maheran Nik Muhammad \\ Universiti Teknologi Mara, Kelantan \\ Kampus Kota Bharu, 15050, Kelantan, Malaysia \\ Tel: 60-1-2966-5402Ｅ-mail: nmaheran@kelantan.uitm.edu.my \\ Muhamad Jantan \\ Corporate and Sustainable Development Division \\ Universiti Sains Malaysia \\ 11800, Minden, Penang Malaysia \\ Tel: 60-1-3480-3069Ｅ-mail: mjantan@usm.my
}

\begin{abstract}
Current thinking in corporate long-range planning tends to emphasize the need for, and value of environmental information. Many scholars proposed that environmental information is crucial to modern corporate planning and for firms to remain competitive, particularly when making capital investment decision. Such information is generated outside the firm's official jurisdiction. Unfortunately, little is known of the extent of environmental scanning done by decision makers when making capital investment decision. This paper reports on a study undertaken to determine the extent of environmental scanning in relations to the quality of investment decision made. This study examines the relationship between environmental scanning behavior and the quality of investment decisions made by managers. Result from 118 questionnaires by higher-level managers in Malaysia show that in making capital investment decision, most of the environmental scanning was related to competitor information, technology information and economic information. Out of this information, information made related to competitors and economics leads to high quality decision.
\end{abstract}

Keywords: Environmental Scanning, Capital Investment, Decision-making Quality 


\section{Introduction}

Managers generally are concerned in making decisions with brilliant outcomes. According to Brower (2000), a good decision or quality decision is a decision that results from a thoughtful decision making process, which emerged from a process of seeking, understanding and using the information effectively in situations of uncertainties. Hence, environmental scanning is one tool in an organization's arsenal that can be used to gain this understanding (Albright, 2004). Environmental scanning is the internal communication of external information about issues that may potentially influence an organization's decision-making process. The scanning behavior of the decision maker such as the amount of scanning done, the scanning methods used to scan the environment, source of information used and the scope of environment scanned, to understand how the environment will impact the decision quality. Thus, this research investigates the impact of the environmental scanning on decision quality, with a specific focus on capital investment decision among Malaysia higher-level executives.

\subsection{Background of the Study}

For more than forty years, there have been periodic reviews of the decision-making literature. In almost six decades since Simon's (1947) seminal critique of the rational model of decision-making, theorists have been trying to replace it with a systematic and coherent explanation of decision-making behavior (Cray, et al., 1991). Over the years, a number of factors have been suggested as being important for understanding a quality strategic decision-making process. Hage (1980) in Cray et al. (1991) states that the frequency of occurrence, cost, continuity with previous issues and risk are important factors in understanding strategic decision-making. MacCrimmon (1985) on the other hand argues that the degree of rationality, informedness, social interest and degree of manipulativeness are the key dimensions of the decision-making context that influenced the outcome of the process. More recent literature by Makadok and Barney (2001) suggests that the process and information quantity are important factors in understanding strategic decision-making. Thus, the quantity and quality of data gathered should commensurate the degree of environmental uncertainty facing the firm to ensure successful decision making.

The extant literature has provided a variety of models regarding managerial decision making. For example, one stream of research suggests that managers process information in an intuitive manner (e.g., Mintzberg, 1988) while another research stream (Thomas, Clark and Gioia, 1993) suggests that managers deliberately seek out and sift through enormous amount of new information in order to make effective decision. Daft and Weick (1984) examine rational data gathering activity which includes environmental scanning. Environmental scanning assesses the internal strengths and weaknesses of an organization in relation to the external opportunities and threats it faces (Abels, 2002). Some believe that supplementing rational data gathering with intuition or tacit knowledge may improve managerial decision-making (Mintzberg, 1988). However, in spite of the many researches on strategic decision making in relation to environmental scanning, no management research has focused on the impact of environmental scanning as an input to the strategic decision-making process to investment decision quality. Issues of the extent of scanning (i.e. amount of scanning, 
formal vs. informal methods) and their impact on the quality of decisions made are amongst issues yet to be fully addressed in the literature on environmental scanning.

\subsection{Motivation of the Study}

In today's corporate world which had and still undergoing unprecedented changes, increasing demand to get strategic investment decision right is enhanced. Companies invest hundreds of billions of dollars every year in fixed assets. By their nature, these investment decisions have the potential to affect a firm's fortunes over several years. A good decision can boost earnings sharply and dramatically increase the value of the firm and bad decision can lead to bankruptcy. Due to this fact, many studies have been done on the importance of strategic decision making to the organizational performance. Many researchers have also deliberated on the theoretical aspects of strategic decision-making and organizational performance. The early studies done by Burns and Stalker (1961), Chandler (1962), Harper (1993), and Lawrence and Lorsh (1967) as cited in Jennings and Lumpkin (1992), find that a firm's high performance depends on its successful corporate strategy and structure. Similarly, Sulaiman (1989) also finds that high performing Malaysian manufacturing firms use the right corporate strategy. However, the effectiveness of the corporate strategy relies on strategic decision making quality; that is the extent to which they result in desired outcome (Sharfman, 1996). According to Hammond, Keeney and Raiffa (1998), bad decisions can often be traced to the way the decisions were made - the alternatives are not clearly defined, the right information is not collected, the cost and benefits are not accurately weighted as well as the biased choice made by the decision maker. This judgmental bias is due to eight traps which are; (1) The anchoring trap - which led the decision maker to give disproportionate importance to the first information they receive; (2) The status quo trap which led the decision maker toward maintaining the current situation even though better alternatives exist; (3) The sink-cost trap - which inclines the decision maker to perpetuate the mistakes of the past; (4) The confirming-evidence trap - which led the decision maker to seek out information supporting an existing predilection and to discount opposing information; (5) The framing trap that occurs when the decision maker misstate problem, undermining the entire decision-making process; (6) The overconfidence trap that biases the decision maker to overestimate the accuracy of their forecast; (7) The prudence trap - which led the decision maker to be overcautious when they make estimates about uncertain events; and (8) Recall ability trap, which led the decision maker to give undue significance to recent and dramatic events. These traps are particularly disastrous in situations of great uncertainties of today's environment.

In order to overcome the traps mentioned earlier, Hammond et al. (1998) suggest that decision makers must be open minded and seek information and opinions from a variety of people (sources) to widen their frame of references and to push their mind in fresh directions. This is called environmental scanning. Environmental scanning is a process of seeking information about events and relationships from a company's external environment (Hambrick, 1981). Knowledge from the information helps the top management to plan for the company's future course of action. Furthermore, environmental scanning is the first step in problem-solving sequence and it influences the perceptions and actions of the organization (Hambrick, 1981; Daft and Weick, 1984). Environmental scanning is also used to reduce uncertainties 
surrounding the decision-making process. Leroy and Bernard (2004), in his study found that environmental scanning could reduce manager's risk-averse attitude in increasing the level of productive investment. Ekmen (2005) in his study of small manufacturing enterprise in the printing and clothing industries also found that owner managers decision making process was based on their past experience or from the experience of others, that is through collection of external information. Thus, environmental scanning can be seen as a mechanism for reducing uncertainty in the decision-making context.

Several studies (Hambrick, 1981, Daft and Weick, 1984 and Venkatraman, 1989) discovered a positive relationship between scanning behavior and performance. According to Dess, (1984) environmental scanning is the primary strategy and is necessary in establishing organizational goals. In addition, it has been found that successful firms differ from unsuccessful firms because they do more scanning and they also have a broader pattern of scanning (Daft, Sormunen and Parks, 1988) as scanning will help decision makers to make a better decision and ultimately a quality decision. Many studies found that high performing companies scanned more frequently and more broadly in response to strategic uncertainty than their counterparts in low-performing companies (Daft et al., 1988 and Beal, 2000). Therefore, it can be assumed that the poor performance of some firms can be attributed, partly if not fully to poor decision making strategy. One of it can be attributed to the lack of environmental scanning.

This research therefore aims to fill such a gap in the research of environmental scanning and strategic decision making by looking at the impact of extent of environmental scanning to investment decision-making quality based on the comprehensiveness of the amount of information that should be scanned, the method of scanning that should be utilized, the source of information that should be used and the sector of environment that should be scanned. Therefore, this research investigates how scanning was done by top management in all types of firms in Malaysia and how it should be done to ensure quality decisions.

\section{Research Methodology}

\subsection{Research Design}

The purpose of this study is to explain the nature of relationships between the extent of environmental scanning and the investment decision quality. Since the focus of this study is on the extent of scanning and its impact, and that the researcher is trying to addresses the questions of types of scanning behavior that organizations should adopt in order to ensure quality decisions, it is therefore be established by engaging hypothesis testing method research design. Cross-sectional survey is the best method available to collect the primary data for describing a population of strategic decision that is too large to observe directly (Choo, 1993). A survey through personal contact and personally distributed questionnaires was carried out to the CEOs or higher-level managers of the companies located all over Malaysia.

The data relates to an investment decision, which therefore forms the unit of analysis. The extent of scanning involved in making the decision and its subsequent quality will be 
measured. The decision as the unit of analysis is chosen to enhance internal validity as choosing the manager or the organization which makes the decisions will only confuse the issues to be addressed. This is due to the fact that managers and organizations make many decisions, some would involve a great amount of scanning, and some none at all, and the associated quality is high for some and low in others. Therefore, isolating the focus on a specific decision, and measuring the associated scanning behavior and quality, will strengthen the validity of the relationship thus established.

\subsection{Variables and Measurement}

The conceptual framework of the study consists of the extent of environmental scanning as the independent variables (i.e amount of scanning, method of scanning ands sources of scanning) and investment decision quality as the dependent variable.

\subsubsection{Amount of Scanning}

The extent of scanning done by managers is one of the common dimensions of scanning behavior used in earlier studies (Sawyer, 1993, Elenkov, 1997 and May et al., 2000). Most of the previous research conceptualized the amount of environmental scanning based on frequency of scanning, interest in scanning and the time spend in scanning the environment (e.g. Ebrahimi,2000; Elenkov, 1997; Hambrick, 1982: May et al.. 2000). However, for the present study, the concept of the amount of scanning is operationalized by measuring the amount of information the managers scan on each type of information needed for the decision they have made. $\quad$ Each type of information scanning is referred to as the scope of scanning.

\subsubsection{Scope of Scanning}

The scope of environmental scanning is concerned with the type of information scanned in response to environmental change or factors. It also shows the purpose of scanning the environment. Scope of environmental scanning can be seen from two dimensions; that are the task environment and the general environment. The former consists of sectors that are involved in direct interactions with the decision made (e.g. suppliers, customers and competitors), whereas latter includes sectors defined as remote environment, having indirect interactions with the decision (such as the government, economic conditions, technology and socio-cultural factors) (Ebrahimi, 1990 and Grant, 1991). The variable that will be used for the scope of environmental scan will follow Daft et al. (1988) and Sawyer (1993), where the environment is subdivided into six sectors: political/legal, economic, technology, socio-cultural, and competition/industry, customer/market. The first four sectors make up the general environment and the last two, the task environment.

\subsubsection{Methods of Scanning}

According to many researchers, the method of scanning will determine the quality of information obtained that directly influence the quality of the decisions made (e.g. Subramanian, Fernandez and Harper, 1993). The popular dimension used to measure method of scanning is formal vs. informal systems and regular vs. irregular basis. The formal system consists of a specialized unit and personnel dedicated to the tasks of acquiring, 
interpreting and internally communicating information on different aspects of the firm's environment (May et al., 2000). With formal system, scanning is usually done on a routine or regular basis where the information will be stored and used whenever needed.

An informal system is built around the day-to-day scanning activities of individual managers and is done on an ad-hoc basis by either middle or top level executives in the organization. The information is obtained on a non-routine or informal basis and is usually gained through chance encounters that do not seek comprehensive hard data. Information seeking is thus casual and opportunistic, relying more on irregular contacts and casual information from external, sources (Choo, 2000).

\subsubsection{Sources of Scanning}

Another dimension of environmental scanning behavior is sources of scanning used. Many literatures have identified several sources of information that can be drawn on in the scanning process. Typically, the sources can be categorized as internal and external sources and as personal and impersonal sources (Aguilar, 1967). Internal sources of information about the external environment includes memos, output from management information systems, and direct contact with managers and employees within the organization (McGee and Sawyer, 2003), while external sources of information which include trade publications, direct contact with customers, suppliers, and executives from other companies as well as attendance at industry-related meetings and seminars as well at the internet (Wood, 1997).

Personal and impersonal sources on the other hand, are operationalized by looking at the types of contacts. Personal sources of information originate from personal contacts involving direct communication with other individuals either within or outside of the organization, such as friends, family members, and close business associates. On the other hand, impersonal sources originate from non-personal sources typically written communications such as formal reports, trade publications, newspapers, government reports, output from management information system and so on (Aguilar, 1967; Daft and Weick, 1984).

Following the work of Hambrick (1981), environmental scanning will be grouped by the type or scope of information, the respondents will be asked to rate the extent of environmental scanning done, method and source of information used on a five-point scale ranging from (1) not at all to (5) great amount, for the extent of scanning; (1) very informal to (5) very formal for method of scanning; and (1) very impersonal to (5) very personal and (1) external to (5) internal for source of information.

\subsubsection{Investment Decision Quality}

Quality investment decision is a decision that: (1) meets (or contributes to the achievement) the objectives of the organization; and (2) gives rise to positive outcome to the decision maker. Therefore quality investment decision is operationally defined by looking at decision-making outcome in differentiating between good decision and bad decision and whether it has met the goal and objective of the organization. To tap into information regarding whether the specific decision has met the relevant objective, quality of decision 
will be broken up into various dimensions such as quality improvement in products/services; improvement in cost efficiency; improvement in timeliness; improvement in profitability; increased expected returns; etc.

The quality of the decision by the respondents depends on two factors. One is the importance of achieving each of the listed objectives, and secondly the extent the objectives were achieved. The Decision Quality Index (DQI) measure used is a weighted sum of the achieved objectives, where the weights are represented by the importance attached to the each of the objectives. The importance ranked from 1 to 10 by forming the weights attached to each of the quality. Since the ranks differ from decision to decision, the quality of the decision is rated based on the respondents' importance attached. Since the weights summed up to $55(10+9+8+7+6+5+4+3+2+1=55)$, the denominator is 55 . Therefore, the Quality index formula is as follows:

$$
\begin{aligned}
D Q I & =\frac{\sum \text { (importance of objective i x achievement of objective i) }}{\sum \text { importance of objective i }} \\
& =\frac{\sum \text { (importance of objective i x achievement of objective i) }}{55}
\end{aligned}
$$

\section{Research Hypotheses}

\subsection{Amount of Scanning}

The literature indicates that the extent of scanning is measured by the frequency of scanning done or the number of times the manager scans the environment to get information. There is a number of evidence that indicate organization which engage more in environmental scanning perform more successfully than their counterparts who do not do so (e.g. Hambrick, 1981; Daft et al., 1988 and Subramaniam et al., 1993; Beal, 2000 and Choo, 2001;). Therefore, the researcher expects that the more the manager scans the environment for information, the more timely information he/she will get to capture the changing trend. This timely information will be useful for the organization to identify problems and opportunities and therefore more able to make the correct decisions. Therefore it is hypothesized that:

H1: The greater the amount of environmental scanning done the better the quality of the investment decision made.

\subsection{Method of Scanning}

Chief Executives of high performing firms have been found to scan the environment more broadly and more regularly and devote more analysis to the key environmental actors than the Chief Executive Officer of low performing firms (Miller and Friesen, 1982; Daft et al., 1988). Thus, most of the authors agree that the environmental scanning process should be conducted on a continuous basis and it is proposed that formal scanning units are adopted to collect strategic information about environmental sector in order to give a positive impact on organizational performance. Therefore, the researcher expects that a formal method will 
give rise to quality decisions as a formal method allows for systematic capture of information, and subsequently better analysis as organizations usually make available expertise and other necessary resources for routine work of the organization. This creates a culture of putting value to information, and thus an internal environment of information enhancement. Such a culture would then acts on such information and this translates to better decisions. Therefore, it is hypothesized that:

H2: Investment decision that relies on information scanned from more formal methods of environmental scanning will be of better quality than those that relies more on informal methods.

\subsection{Sources of Information Scanned}

Sources of strategic information have generally been classified into four broad categories; external, internal, personal and impersonal. There appears to be a general agreement in the literature (Aguilar, 1967; Churchill and Lewis, 1993; Elenkov, 1997; Keegan, 1974) on the importance of external and personal sources over internal and impersonal sources in obtaining external information. This is because decision makers usually know internal information; whereas external information enriches the body of information on which to base the decision on. Furthermore, strategic information is usually about external environment, which may or may not be known to members of the organization. Also, investment decisions are not independent of what is happening outside the organization. Besides, external information provides greater diversity of information and thus avoids the situation of "status quo" decisions if decisions are to be made based upon internal information only. Therefore it is hypothesized that;

H3a: Investment decision that utilizes more external sources of information will be of better quality than investment decision that utilizes more internal sources; the more external sources used; the better would be the investment decision.

As for personal versus impersonal information, personal information is more tacit in nature as compared to impersonal ones. This tacit nature provides for unique information, not available to just anyone, and therefore provides for competitive advantage over those not privy to it. Thus, personal information is of greater value due to its rarity and difficulty to replicate. Therefore, it is hypothesized that;

H3b: Investment decision that utilizes more personal sources of information will be of better quality than investment decision that utilizes more impersonal sources; the more personal sources used; the better would be the investment decision.

\section{Research Findings}

354 questionnaires were distributed via convenient sampling and out of which, 126 were returned. Thus, the total response rate was 37\%. However, the final sample size used for data analysis was 118.

In terms of who made the decision, the majority of the decision-makers in our sample holds managerial position (39\%) designated in most of the business units such as regional manager, 


\section{Macrothink}

Journal of Management Research

ISSN 1941-899X

2009, Vol. 1, No. 1: E4

branch manager, operation manager, financial manager and so on. followed by CEOs (33\%). Furthermore, $45 \%$ of the sampled decisions is made by large companies in operation for more than 15 years. Based on the decision profile, most of the decisions in the sample are related to capital acquisitions (35\%) involving decisions to acquire plant, machinery, building, land, computers, and etc., and $28 \%$ are related to decisions about research and development, developing new product and new market and so on. Another $22 \%$ is the decision related to business acquisition and mergers while $14 \%$ is related to market expansion. Hence, the study covers a whole spectrum of decisions which hopefully will reflect the various types of scanning behavior.

The size of investment involved in the decisions was seen to be more on the low end, with $40 \%$ involving an investment of RM1 million or less, and only 20\% is of investments value at RM20 million or more. Table 4.4 displays the decision profile of the research sample.

\subsection{Descriptive Analysis}

After running factor analysis, the factor loadings are in the range of 0.582 to 0.923 loaded for only three components. Thus, the hypothesized five dimensions for scope of information (i.e. technology, economic, regulation, competition and socio-cultural factors) are now reduced to only three dimensions. These three are then labeled as technology, economic/financial, and competition information on the basis of the items loaded onto them. Reliability test shows a Cronbach-alpha of more than 0.6 for each factor indicating an existence of internal consistency among the items.

In gaining insight into how and how much of the business environment was scanned when making investment decisions, the overall sample was examined. Specific items of interest are shown in Table 1 below. The mean level of environment being scanned and its dimensions are slightly above 3 indicating a moderate level of scanning done (mean $=3.37$ ). Furthermore, the extent that the three sectors (technology, economic and competition) of the environment are scanned do not differ by much; indicating that overall, the three sectors are equally scanned for information when making the decisions. 
Table 1. Descriptive statistics of Independent Variables

\begin{tabular}{|c|c|c|}
\hline \multicolumn{3}{|l|}{ Decision $N=118$} \\
\hline Variables & Mean & $\begin{array}{l}\text { Std. } \\
\text { Deviation }\end{array}$ \\
\hline \multicolumn{3}{|l|}{ X1: Extent of scanning } \\
\hline Technology & 3.369 & .985 \\
\hline Economic/financial & 3.371 & .988 \\
\hline Competition & 3.392 & .936 \\
\hline \multicolumn{3}{|l|}{ X2: Methods of scanning } \\
\hline Technology & 3.413 & 1.046 \\
\hline Economic/financial & 3.469 & .848 \\
\hline Competition & 3.405 & .752 \\
\hline \multicolumn{3}{|l|}{$\begin{array}{l}\text { X3: Sources of } \quad \text { scanning } \\
\text { (Personal/Impersonal) }\end{array}$} \\
\hline \multirow{3}{*}{$\begin{array}{l}\text { Technology } \\
\text { Economic/financial } \\
\text { Competition }\end{array}$} & 2.913 & .743 \\
\hline & 2.989 & .863 \\
\hline & 3.068 & .767 \\
\hline \multicolumn{3}{|l|}{ X4: Source of $\quad$ scanning } \\
\hline Technology & 3.047 & .917 \\
\hline $\begin{array}{l}\text { Economic/financial } \\
\text { Competition }\end{array}$ & 2.867 & .747 \\
\hline
\end{tabular}

Notes: X1 scale range: 1 (not at all) to 5 (great amount)

X2 scale range: 1 (informal) to 5 (formal)

X3 scale range: 1(impersonal) to 5 (personal)

X4 scale range: 1 (external) to 5 (internal)

Similarly, the methods used to scan the environment do not vary much across the three types (or sectors) of the environment. The methods used to scan for information are moderately formalized (mean $=3.43$ ). Thus, one can conclude that a combination of both formal and informal methods is used to scan the environment.

Sources used to gather information. A similar pattern is found in all three sectors of environment. The mean level of about three indicates that a combination of personal and impersonal sources is used across all three sectors of information. A similar situation occurs for external and internal sources. However, competition information were found to utilized more informal method and through impersonal sources. 


\subsection{Inferential Analysis}

Table 2. Model summary of multiple regression analysis

\begin{tabular}{|l|l|}
\hline & DECISION QUALITY \\
\hline F value & $2.579 * * *$ \\
\hline R square & .258 \\
\hline Adjusted R square & .158 \\
\hline R square change & .258 \\
\hline F change & $2.809 * * *$ \\
\hline
\end{tabular}

\begin{tabular}{|r|c|}
\hline Independent Variables & $\begin{array}{l}\text { Standardized } \\
\text { coefficients }\end{array}$ \\
\hline Extent of scanning & \\
Technology & -.075 \\
Economic & $.408^{* * *}$ \\
Competition & $.182^{*}$ \\
\hline Method of scanning & \\
Economic & -.148 \\
Competition & $.199 *$ \\
\hline Technology & -.101 \\
Economic & .041 \\
Competition & .033 \\
\hline Source (P/IP) of scanning & \\
Technology & .031 \\
Economic & -.139 \\
\hline
\end{tabular}

$* * *$ significant at $<0.00, * *$ significant at $<0.05$, *significant at $<0.1$

The determinants of the relationship between environmental scanning and investment decision quality are based on the results in Table 2 . R-square of 0.258 , indicate that $25.8 \%$ of the variance in the quality of the decision can be explained by the variations in the extent, method and sources of scanning variables. The significant F-statistics (2.809) also indicates that a model exists.

Standardized $(\beta)$ coefficients from the regression analysis that describe how strongly the independent variables influenced the dependent variables indicates that the extent of scanning 
with regards to economic information and competition information is significant and has positive relationship with the investment decision quality. Furthermore, the higher beta value shows that the amount of scanning for economic information has the most significant impact in explaining the variance in decision quality, followed by scanning the competition information. However, scanning of technology information has no impact on the decision quality. Hence, an alternate hypothesis of $\mathrm{H} 1 \mathrm{a}$ is not supported but the hypotheses of $\mathrm{H} 1 \mathrm{~b}$ and $\mathrm{H} 1 \mathrm{c}$ are supported.

With regards to the method of scanning, the only method used to scan competition information has significant and positive relationship with decision quality. Although it is weak (significance level of 0.10), competition information has little impact in explaining the variance in decision quality. Its positive direction indicates that the more formal the method used to scan competition information, the better will be the quality of decision. Therefore, alternate hypothesis $\mathrm{H} 2 \mathrm{c}$ is supported and $\mathrm{H} 2 \mathrm{a}$ and $\mathrm{H} 2 \mathrm{~b}$ are not supported.

For sources of information, the regression analysis results indicate that no significant relationship exists across the various types of information. This indicates that all alternate hypotheses $H 3$ and $H 4$ are not supported.

\section{Discussion}

On the basis of this study for investment decision making in all industry sectors, it can be concluded that the effects of scanning do not impact investment decision quality by much except for the economic and competition information analyzed. The method of scanning used only affects the decision quality on the formality of method used to scan competition information. Sources of scanning on the other hand do not impact the decision quality at all. This is also reflected in the lower extent of scanning for technology information and rated the least important.

Indeed, the findings suggest that decision makers who concentrate more on the information related to the area such as competitive trend, values and product as well as economic and financial management will have a higher decision quality. This is consistent with the findings of Yunger (2005), who also finds that decision makers in Malaysian organization require constant attention to competitors as well as economic changes that are impacting new product design and delivery. The main effect shows that, decisions that are scanned (and subsequently used) information from these sectors experienced high decision quality.

However, the absence of significant impact of technology to investment decision making does not necessarily mean that technology information has no impact on the quality of decisions; it could be due to the presence of other variables which contribute to the variance of the decision quality. Since the extent of technology information scanned is correlated to that of extent of economic and competition information scanned, the impact of technology information on decision quality may be subsumed within the impact of the other two types of information scanned.

Although competition information and economic information have direct impact on quality decision, only formality of the method used to scan competition information has positive 
impact on investment decision quality. The finding suggests that a more formal method of scanning for competition information will contribute to better decisions. This is due to the fact that the nature of competition information. Under a normal situation, it is usually scanned informally. Therefore, extra effort using systematic formalized method will provide a competitive edge resulting in better quality decisions. Hence, the more formal method used to scan competition information, the better the quality of investment decision.

Sources of information on the other hand have no impact at all to the investment decision quality. Therefore, regardless of what sources of information used to scan the environment (personal, impersonal, external or internal), the decision quality remains invariant. This may be due to the impact is subsumed by the types of information and extent of scanning done. It does not matter how one gets the information, as long as it is sufficient and of quality. Thus, sources of information will determine the amount and quality of information and further, it is the amount (extent) and quality of information that is impacting the decision quality. When taken simultaneously with all the other variables, the variable of source of information is not significant as its impact is indirect through the extent of information scanned.

Since the impact of scanning on investment decision quality remains largely unexplored, therefore no comparison of the present findings can be made to previous relevant literature. However, there are researches on the environmental scanning/performance relationship as well as scanning/strategy relationship. Based on these two streams of research, some inferences may be deduced regarding the scanning-decision quality relationship. Miller (1989); Jennings and Lumpkin (1992) and Subramaniam et al. (1993) find positive relationship between scanning and performance although Hambrick (1981) fails to find such relationship between the different strategies employed by a firm and scanning behaviors. Combining the scanning stream of research with the scanning-decision quality research, it can be argued that the positive relationship between scanning and decision quality in the present study is consistent with the previous study of Subramaniam et al. (1993) and the others.

\section{Implication of the Study and Conclusion}

Scanning is an important first step in the strategic decision-making process, which influences the perception and action of the organization (Hambrick, 1981; Daft and Weick, 1984). That is, managers scan the environment, they make judgments, and these judgments affect organizational outcomes. However, many of these studies have focused on decisions related to the choice of corporate strategies, and there is certainly a dearth of literature that focused on strategic investment decisions, which is the primary focus of this study. Thus the findings of this study will further add to the literature with in-depth understanding of scanning and its differential impact on the quality of decision. The findings suggest that the scanning behavior does not vary by types of information scanned, and that different information scanned has different impact on the quality of the decision made.

Furthermore, for practical reasons, the differences in scanning behavior provide clues that can be beneficially utilized when designing effective management information systems for 
organizational decision making. For example, since more quality decision is achieved from using the formal method to scan competition information, it can be suggested that, such systems should be designed to ensure that executives used more formal methods to scan the relevant information. Similarly, since personal/impersonal and external/internal information have no impact on the decision quality - this would then implies that irrespective of the sources used - as long as the extent of scanning done is high, the decision quality will improved - thus when designing Information Systems, it can also be designed to capture information from as many sources as possible not just one particular source.

In general, a direct linkage is found between decisions and scanning among top executives. However, only certain information and method are used to impact quality decision. These findings suggest primary implications for executives responsible for investment decision-making. The implication is that some executives may have fallen short in arriving at decision to scan the type of information and amount of information needed as well as method used suitable to achieve quality decision. Whether the downfall rests on the failure to choose the right information for the specific decision made, or the failure to obtain right data and broad understanding of the data within the environment, is open to question. Therefore, this research indicates that executives should scan their organization's environment in ways that directly impact a quality decision.

\section{References}

Abels, E. (2002). Hot Topics: Environmental Scanning. Bulletin of the American Society for Information and Science and Technology. 28(3), 1-4.

Aguilar, F.J. (1967). Scanning the business environment. New York: McGraw-Hill.

Albright, S.K. (2004). Environmental scanning: Radar for success. The Information Management Journal, 38-45.

Auster, E., \& Choo, C.W. (1993). Environmental Scanning by CEOs in two Canadian industries. Journal of the American Society for Information Science, 44(4): 194-203.

Beal, R. M. (2000). Competing Effectively: Environmental Scanning, Competitive Strategy, and Organizational Performance in Small Manufacturing firms. Journal of Small Business Management, 27-45.

Choo, C.W. (2001). Information Management for the Intelligent Organization: The Art of Scanning the Environment. Medford, N.J.: Information Today Inc.

Choo, C.W. (2001). Environmental scanning as information seeking and organizational learning. Information Research, 7(1). http://InformationR.net/ir/7-1/paper112.html].

Choo, C.W. (1993). Acquisition and Use of Information by CEOs in the Canadian Telecommunications Industry. PhD Dissertation, University of Toronto.

Churchill, N. \& Lewis, V. (1993). The five stages of Business Growth. Harvard Business Review, 61(3), 24. 
Chandler, A.D. (1962). Strategy and Structure. Cambridge, MA: MIT Press.

Cray, D., Mallory, G.R., Butler, R.J., Hickson, D.J. \& Wilson, D.C. (1991). Explaining Decision Process. Journal of Management Studies, 28(3), 0022-2380.

Cyert, R.M., \& March, J.G. (1989). The Behavioral Theory of firm. 2 Edition, Oxford, UK: Blackwell.

Daft, R.L., Sormunen, J. \& Parks, D. (1988). Chief executive scanning, environmental characteristics, and company performance: an empirical study. Strategic Management Journal 9, 123-139.

Daft, R.L. \& Weick, K.E. (1984). Toward a model of organizations as interpretation systems. Academy of Management Review, 284-295.

Ebrahimi, B.P. (2000). Perceived Strategic Uncertainty and Environmental Scanning Behavior of Hong Kong Chinese Executives. Journal of Business Research 49(1), 67-78.

Elenkov, D.S. (1997). Strategic uncertainty and environmental scanning: The case for institutional influence on scanning behavior. Strategic Management Journal, 18, 287-302.

Grant, R.M. (1991). The resource-based theory of competitive advantage: implications for strategy formulation. California Management Review, 114-135.

Hambrick, D.C. (1981). Specialization of environmental scanning activities among upper level executives. Journal of Management Studies, 18(3), 299-320.

Hambrick, D.C. (1984). Environmental Scanning and Organization Strategy. Strategic Management Journal, 3, 157-174.

Hambrick, D.C., and Mason, P. (1984). "Upper Echelons”: the Organization as a Reflection of its top Managers.” Academy of Management Review 9, 193-206.

Hammond, J.S., Keeney, R.L. \& Raiffa, H. (1998). The Hidden Traps in Decision Making. Harvard Business Review, 76(5). 102-126.

Jennings, D.F. \& Lumpkin, J.R. (1992). Insights between Environmental Scanning Activities and Porter’s Generic Strategies: An Empirical Analysis. Journal of Management 18, 761-803.

Keegan, W.J. (1974). Multinational Scanning: A study of the information sources utilized by headquarters executives in multinational companies. Administrative Science Quarterly, 19: 411-42.

Leroy, S. \& Bernard, J. (2004). Managers and productive investment decisions: the impact of uncertainty and risk aversion. Journal of Small Business Management.

MacCrimmon, K.R. (1985). Understanding Strategic Decisions: Three systematic approach. In Penning, J.M. (Ed), Organizational Strategy and Change. San Francisco: Jossey-Bass.

Makadok, R. \& Barney, J. (2001). Strategic factor Market Intelligence: An Application of Information Economics to Strategy Formulation and Competitor Intelligent. Management 
Science 47, 1621-1638.

May, R.C., Stewart, W.H.J. \& Sweo, R. (2000). Environmental scanning behavior in a transitional economy: evidence from Russia. Academy of Management Journal, 43(3), 403-427.

McGee, J.E. \& Sawyerr, O.O. (2003). Uncertainty and Information Search Activities: A study of owner-managers of small high-technology manufacturing firms. Journal of Small Businesses Management 41(4), 385-401.

Miller, D. \& Friesen, P.H. (1982). Innovation in conservative and entrepreneurial firms: Two models of strategic momentum. Strategic Management Journal, 3, 1-25.

Mintzberg, H. (1988). Generic Strategies toward a Comprehensive Framework. Advances in Strategic Management 5, 1-67.

Sawyerr, O.O., Ebrahimi, B.P. \& Thibodeaux, M. S. (2000). Executive Environmental Scanning, Information Source Utilization, and Firm Performance: the case of Nigeria. Journal of Applied Management Studies, 9(1), 95-115.

Sawyerr, O.O. (1993). Environmental uncertainty and environmental scanning activities of Nigerian manufacturing executives: a comparative analysis. Strategic Management Journal, 14(4), 287-299.

Sharfman, D. J. W. (1996). Does Decision Process Matter? A study of strategic decision-making effectiveness. Academy of Management Journal, 39(2), 368-377.

Subramaniam, R., Fernandez, N. \& Harper, E. (1993). Environmental scanning in US companies: their nature and their relationship to performance. Management International Review, 33(3), 271-286.

Sulaiman, M. (1989). Corporate Strategy and Structure of High Performing Manufacturing Firms. PhD Thesis, University of Wales, U.K.

Thomas, P. S. (1980). Environmental Scanning: The State of Art. Long Range Planning, 13(1), 20-25.

Venkatraman, N. (1989). Strategic Orientation of Business Entreprises: The Construct, Dimensionality and Measurement. Management Science 35(8), 942-962.

Yunger, M. (2005). Environmental Scanning for Strategic Information: Content analysis from Malaysia. Journal of American Academy of Business, Cambridge 6(2). 02-17. 